\title{
A STATISTICAL ANALYSIS OF THE EFFECTIVENESS OF SELECTED METHODS IN THE TEACHING OF MATHEMATICS
}

We present the results of pedagogical experiment, which has verified the effectiveness of three teaching procedures used to teach selected units of secondary school mathematics. The primary experiment was preceded by a pilot survey realized among 200 first-grade students of the University in Zilina. The aim of the survey was a determination of the degree of contingency between two qualitative signs: the level of understanding mathematics and the teaching style in the teaching of mathematics. Regarding the obtained results the statistical methods of the single-factor analysis of variance for balanced model and Duncan's multiple range test were used to specify the most effective teaching method. The results of the experiment unambiguously confirm the teaching supported by the use of information technologies as the most effective method in the teaching of mathematics.

Keywords: pedagogical experiment, teaching method, information technologies, qualitative research, contingency coefficient, one-factor dispersion analysis, Duncan's multiple range test, observability of the effectiveness of teaching methods.

\section{Introduction}

The problem of students' understanding and mastering mathematics is currently one of the most emphasized topics of expert public discussion. New ways of teaching mathematics more effectively and attractively are being searched for. The information society brings new alternatives nowadays; it enables us to change established and rigid forms and methods in teaching. The veracity of a statement that the integration of information technologies into the process of education means the advent of new era of effective teaching and learning has been already proved by numerous research projects here and abroad. Many of them, for example [1], have verified the hypothesis claiming the possibility of computers to change out-of-date pedagogical approach and improve the results of students radically.

However, the technologies themselves are not all-powerful and the informatization of pedagogical process only is not enough. While trying to achieve better results it is necessary to appeal to the change of learners' attitude, their personal engagement and motivation. Only the synchronization of modern technologies together with student activity and participation can lead to better results in mathematical education.

\section{Pilot survey - the teaching style matters!}

While searching an answer to the question why the student attitudes toward mathematics are so often negative and what could influence this situation in a positive way, we conducted a survey realized under the program ITMS Flexible and attractive study at the University of Zilina for the needs of the market and knowledgebased society.

The paper presents one of the partial outcomes, which has ensued from the data obtained in the project realization. 200 students from three faculties of the University in Zilina were addressed in the survey (Faculty of Civil Engineering, Faculty of Operation and Economics of Transport and Communications, Faculty of Special Engineering), in which their attitudes toward mathematics were detected as well as the factors determining these attitudes. The obtained results were used to formulate a hypothesis: the teaching style of mathematics has a significant influence on learning results in mathematics.

Regarding $n=200$ we observed two qualitative characters $A$ and $B$, which took 5 levels.

Character $A$ denotes the teaching style of mathematics (how perceived by students: appropriate - impropriate).

Character $B$ denotes students' level of understanding mathematics.

Character $A$ takes the categories $A_{1}=$ excellent, $A_{2}=$ very good, $A_{3}=$ sometimes convenient, sometimes inconvenient, $A_{4}=$ mostly inconvenient, $A_{5}=$ absolutely inconvenient.

Character $B$ takes the categories $B_{1}=$ subject matter always understood, $B_{2}=$ subject matter understood most of the time, $B_{3}=$ subject matter understood on $50 \%$ of lessons, $B_{4}=$ subject matter rarely understood, $B_{5}=$ subject matter never understood.

\footnotetext{
* Lydia Kontrova, Tomas Lengyelfalusy, Dana Lengyelfalusyova

Faculty of Humanities, University of Zilina, Slovakia, E-mail: lydia.kontrova@fpv.uniza.sk
} 
In relation to the observed categories we have acquired these absolute frequencies:

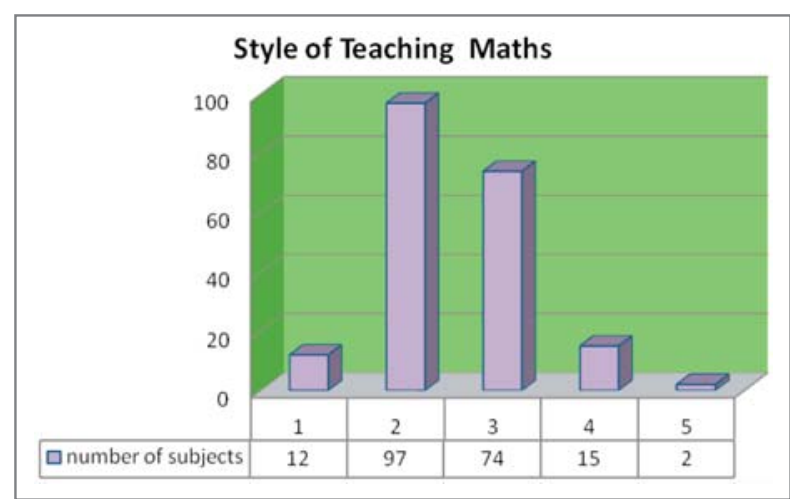

Fig. 1 The observed frequencies of the character $A$

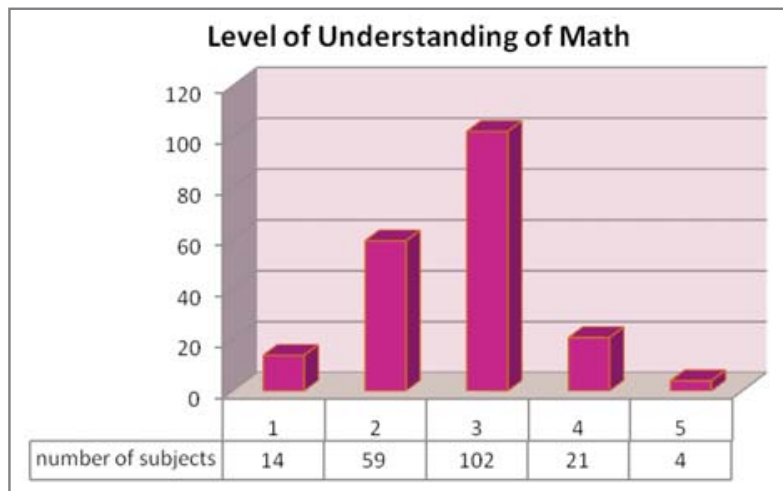

Fig. 2 The observed frequencies of the character $B$

We tested the hypothesis $H_{0}$ on the independence of observed characters $A$ and $B$.

The data acquired from the Fig. 1 and Fig. 2 were used to configure the contingency table (Table 1) for qualitative research of observed characters:
Contingency Table of The Observed

Tab. 2 and Expected Frequencies

\begin{tabular}{|c|c|c|c|c|c|}
\hline$A \backslash B$ & $B_{1}$ & $B_{2}$ & $\cdots$ & $B_{m}$ & $f_{i}^{A}$ \\
\hline$A_{1}$ & $f_{11}\left(o_{11}\right)$ & $f_{12}\left(o_{12}\right)$ & $\cdots$ & $f_{1 m}(1 m)$ & $f_{1}^{A}$ \\
$A_{2}$ & $f_{21}\left(o_{21}\right)$ & $f_{22}\left(o_{22}\right)$ & $\cdots$ & $f_{2 m}\left(o_{2 m}\right)$ & $f_{2}^{A}$ \\
$\vdots$ & $\vdots$ & $\vdots$ & $\vdots$ & $\vdots$ & $\vdots$ \\
$A_{k}$ & $f_{k 1}\left(o_{k 1}\right)$ & $f_{k 2}\left(o_{k 2}\right)$ & $\cdots$ & $f_{k m}\left(o_{k m}\right)$ & $f_{k}^{A}$ \\
\hline$f_{j}^{B}$ & $f_{1}^{B}$ & $f_{2}^{B}$ & $\cdots$ & $f_{m}^{B}$ & $n$ \\
\hline
\end{tabular}

We put the data into the Table $2: f_{i j}$ - the observed frequencies and $o_{i j}$ - the expected frequencies of the characters $A$ and $B$ for $i=1,2,3,4,5, j=1,2,3,4,5$.

We counted the values as follows:

$f_{i}^{4}=\sum_{j=1}^{5} f_{i j}$ a frequency of a category $A_{i}$ of the character $A$, $\sum_{j=1} i=1,2,3,4,5$

$f_{j}^{B}=\sum_{i=1}^{5} f_{i j}$ a frequency of a category $B_{i}$ of the character $B$, $n=\sum_{i=1}^{5} \sum_{j=1}^{5} f_{i j}$

and the expected frequencies $o_{i j}=\frac{f_{i}^{A} \cdot f_{j}^{B}}{n}$ for $i=1,2,3,4,5$, $j=1,2,3,4,5$.

We get the contingency table in the form:

The statistic chi-squared test $\chi^{2}$ was used as a criterion for testing, given as

$$
\chi^{2}=\sum_{i=1 j=1}^{5} \sum_{j=1}^{5} \frac{\left(f_{i j}-o_{i j}\right)^{2}}{o_{i j}}
$$

Test statistic has $\chi^{2}$ division with the number of degrees of freedom $r=16$. The verified hypothesis $H_{0}$ is rejected at the significance level $\alpha=0.01$, if the value of tested criterion is $\chi^{2}>$ $>\chi_{0.01}^{2}(16)$. The critical value is $\chi_{0.01, k r i t i k}^{2}(16)=32.1$.

\begin{tabular}{|l|c|c|c|c|c|c|}
\hline \multirow{2}{*}{$\begin{array}{c}\text { A - the teaching style } \\
\text { of mathematics }\end{array}$} & \begin{tabular}{c}
$|c|$ \\
\cline { 2 - 7 } \\
always understood
\end{tabular} & $\begin{array}{c}\text { Subject matter } \\
\text { understood most } \\
\text { of the time }\end{array}$ & $\begin{array}{c}\text { Subject matter } \\
\text { understood on 50\% } \\
\text { of lessons }\end{array}$ & $\begin{array}{c}\text { Subject matter rarely } \\
\text { understood }\end{array}$ & $\begin{array}{c}\text { Subject matter never } \\
\text { understood }\end{array}$ & $\Sigma$ \\
\hline Excellent & $1(0.84)$ & $7(3.54)$ & $3(6.12)$ & $1(1.26)$ & $0(0.24)$ & 12 \\
\hline Very good & $8(6.79)$ & $27(28.6)$ & $52(49.5)$ & $9(10.1)$ & $1(1.94)$ & 97 \\
\hline Average & $2(5.18)$ & $23(21.8)$ & $40(37.7)$ & $7(7.77)$ & $2(1.48)$ & 74 \\
\hline Mostly inconvenient & $2(1.05)$ & $2(4.4)$ & $7(7.65)$ & $41(1.57)$ & $0(0.3)$ & 15 \\
\hline Absolutely inconvenient. & $1(0.14)$ & $0(0.6)$ & $0(1.1)$ & $0(0.2)$ & $1(0.04)$ & 2 \\
\hline$\Sigma$ & 14 & 59 & 102 & 21 & 4 & 200 \\
\hline
\end{tabular}


For the calculation of test statistic's value the Excel program was used. By putting the CHITEST function for the enter data and at the output configuration we obtained the value $\chi^{2}=45.156$ and the value of probability $p=0.000131$. As $p<0.01$ on the significance level $\alpha=0.01$, we reject the hypothesis on the independence of observed characters. This means that the teaching style of mathematics has a statistically significant influence on the level of understanding mathematics.

The degree of statistical dependence between the observed qualitative characters $A, B$ was consequently analyzed by the contingency coefficient defined by the formula:

$$
C=\sqrt{\frac{\chi^{2}}{n+\chi^{2}}} .
$$

The value of the contingency coefficient is

$$
C=\sqrt{\frac{45.156}{200+45.156}} \cong 0.439
$$

From the calculated value of the contingency coefficient $C$ ensues the fact that there is a mild degree of interconnection between the teaching style of mathematics and the level of understanding mathematics.

\section{A method is not the method}

The results of qualitative analysis of the characters $A$ and $B$ confirm ambiguously the significant influence of a teaching method on the level of knowledge acquired during teaching mathematics. So the myths that mathematics is inborn or one can master mathematics and another cannot are partially disproved [2].

Mathematics is a specific subject. To have a number of relevant information, to know the facts or isolated terms, to recall mathematical sentences, definitions or formulas is only the first step. The cardinal necessity is to understand their mutual context, which is the only source of true knowledge also applicable in reality.

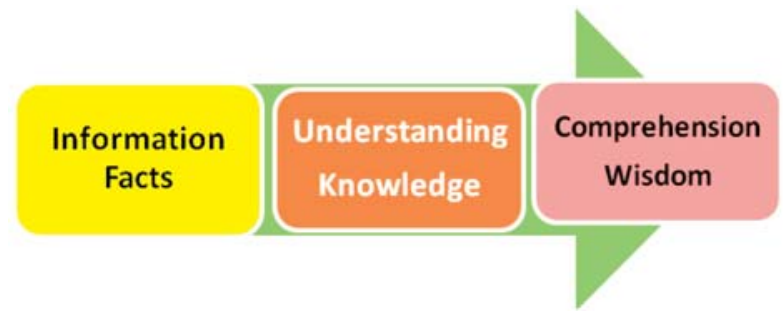

Fig. 3 The scheme of cognitive process

If we want to progress in the field of teaching mathematics, we need to use the methods, forms and means of teaching, which would motivate students to be active, creative and engaged. As written by Piaget, 50 years of experimenting has taught us that there is no knowledge resulting only from the recording of observed phenomena without being structured by the activity of learner [3].
These indicia led our realization of a key pedagogical experiment, which was conducted at three secondary schools in the Zilina region. The experiment has confirmed the relevant influence of one of three applied teaching methods on the effectiveness of teaching mathematics. It has also shown the fact that if the teaching method is convenient and the means and forms of education are appropriate, the effectiveness of teaching increases and the learning results improve.

In connection with the results of the pilot survey we compared the effectiveness of three different teaching methods $A, B$ and $C$.

- Method A: Dynamic form of teaching, the classwork was conducted in a computer classroom. Students actively participated in the process of discovering new mathematical terms. The aim of the activities realized at the lessons of mathematics was a creative search of answers, revealing of terms' interconnection and learning by doing [4].

- Method B: Teaching supported by the use of information technologies; these were used mainly by the teachers for a showy and effective visualization and presentation of curriculum; (Power Point presentations, animations, mathematical applets).

- Method C: Classical transmissive teaching in which traditional teaching means were used, e. g. explanation of curriculum by the teachers, work with textbook, workbook or board.

For the purposes of the experiment we randomly chose the group of 84 students from the $5^{\text {th }}$ grade of 8 -year secondary grammar schools from the Zilina region. The group was further divided into three groups of 28 students. All the students were taught the following thematic unit: Linear functions, equations and inequalities. The number of lessons, scope and content were the same for each group. The students wrote a test afterwards, which consisted of 15 tasks. The tests were evaluated and the results were presented in points (the maximum number of points was 35 ). The results are entered into the Table 3.

For a statistical evaluation of the results obtained in the experiment we used one - factor dispersion analysis. We expected that the level of the mean of three basic complexes depends on one factor - teaching style of mathematics taking three ranks.

For an application of the statistical method of one - factor dispersion analysis three conditions were necessary:

a) Selected samples come from basic complexes with normal division.

b) Selected samples are independent.

c) Dispersions of basic complexes are equal.

The observed character $X$ denoted the level of students' knowledge reached in the posttest. The measured values represent the realization of mutually independent and random selections from the basic complexes, in which the observed sign $X$ has a normal division $N\left(\mu_{1}, \sigma_{1}^{2}\right), N\left(\mu_{2}, \sigma_{2}^{2}\right), N\left(\mu_{3}, \sigma_{3}^{2}\right)$.

$\mu_{1}$ denotes the average level of students' knowledge taught by the teaching method $A$,

$\mu_{2}$ denotes the average level of students' knowledge taught by the teaching method $B$, 
Results of the tests in points

Tab. 3

\begin{tabular}{|c|c|c|c|}
\hline \multirow{2}{*}{ Student } & \multicolumn{3}{|c|}{ Experimental group } \\
\hline & Group A & Group B & Group C \\
\hline 1 & 31 & 21 & 21 \\
\hline 2 & 26 & 19 & 18 \\
\hline 3 & 31 & 31 & 23 \\
\hline 4 & 21 & 13 & 20 \\
\hline 5 & 16 & 20 & 12 \\
\hline 6 & 32 & 19 & 23 \\
\hline 7 & 19 & 20 & 19 \\
\hline 8 & 33 & 31 & 21 \\
\hline 9 & 34 & 31 & 20 \\
\hline 10 & 23 & 18 & 15 \\
\hline 11 & 19 & 21 & 14 \\
\hline 12 & 20 & 17 & 32 \\
\hline 13 & 17 & 16 & 34 \\
\hline 14 & 33 & 32 & 19 \\
\hline 15 & 34 & 11 & 25 \\
\hline 16 & 28 & 29 & 20 \\
\hline 17 & 27 & 19 & 19 \\
\hline 18 & 10 & 34 & 12 \\
\hline 19 & 23 & 18 & 19 \\
\hline 20 & 17 & 14 & 13 \\
\hline 21 & 18 & 16 & 11 \\
\hline 22 & 21 & 11 & 19 \\
\hline 23 & 24 & 19 & 25 \\
\hline 24 & 19 & 15 & 31 \\
\hline 25 & 19 & 12 & 10 \\
\hline 26 & 21 & 11 & 33 \\
\hline 27 & 35 & 34 & 12 \\
\hline 28 & 34 & 19 & 21 \\
\hline Average $\bar{x}$ & 24.42857 & 20.39286 & 20.0357 \\
\hline
\end{tabular}

$\mu_{3}$ denotes the average level of students' knowledge taught by the teaching method $C$.

To verify the first condition - the selected samples come from the basic sample with normal division, the Shapiro-Wilk test for the distribution of a random variable $n \in\langle 7,30\rangle$ was used. The test confirmed the normality of selective complexes [6].

The second condition - the selected samples are independent, was accomplished in relation to the construction of random variables.

For the verification of the third condition - the dispersions of basic samples are equal - we used the Cochran $G$ - test for the equality of dispersions [5].
We tested the hypothesis $H_{0}$ : the dispersions of basic sample are the same, versus to $H_{1}$ : the dispersions of basic samples are different.

We test characteristics $G$ that are given as

$$
G=\frac{\max \left(s_{1}^{2}, s_{2}^{2}, \ldots, s_{m}^{2}\right)}{\left(s_{1}^{2}+s_{2}^{2}+\ldots+s_{m}^{2}\right)} .
$$

$S_{j}$ is the standard deviation of data set $\mathrm{j}$ and $G_{a, m, n-1}$ is the tabulated critical value.

The verified hypothesis $H_{0}$ is rejected at the significance level $\alpha=0.01$, if the value of tested criterion $G \geq G_{a, m, n-1}$.

$G_{0.01, m, n-1}=0.4748$ is the tabulated critical value for $m=3$ and $n-1=27$ the number of degrees of freedom.

The value of the testing characteristics $G=0.374$.

Hypothesis $H_{0}$ is not rejected at the significance level $\alpha=0.01$. The assumption of the equality of dispersions for all three basic samples has been proved.

After the verification of conditions a) - c) we preceded to the one - factor analysis of variance for balanced attempt as the compared samples have normal dispersion and the dispersions of basic samples are equal.

Tested hypothesis:

$H_{0}: \mu_{1}=\mu_{2}=\mu_{2}$ versus to the alternative hypothesis $\sigma_{2}^{2}, \sigma_{3}^{2}$

$H_{1}$ : not all $\mu_{i}$ are equal providing the dispersion equality $\sigma_{1}^{2}$,

As for the spans $n_{1}, n_{2}, n_{3}$ of selected samples $n_{1}=n_{2}=n_{3}=$ $=n=28$ we used the one-factor Analysis of Variance of balanced model. The calculation was realized in the MS Excel program. We employed ANOVA function for the significance level $\alpha=0.05$.

The output table of the one-factor analysis of variance consists of two parts; the values of descriptive characteristics of specific factor levels are calculated in the first part (size of the samples, average and dispersion of the samples).

The second part contains total sum of squares $(S S)$, the numbers of degrees of freedom $(d f)$, the mean square of variance $(M S)$, the value of testing criteria $F=3.4361$ and the critical value $F_{\text {crit }}(2.82)=3.1093$.

As $F>3.109$ is valid, we reject the $H_{0}$ hypothesis at the significance level $\alpha=0.05$, which means that the effectiveness levels of three teaching methods A, B and C are significantly different. The same result is obtained by the use of the value Value $P$. As the value $P=0.0369$, the value of error we get if the null hypothesis is rejected is approximately $3.6 \%$, which is allowable error rate at the significance level $\alpha=0.05$

We summarized of the obtained data: 
ANOVA One Factor

Anova table - the values of the descriptive characteristics

Tab. 4

\begin{tabular}{|c|c|c|c|c|}
\hline Groups & Count & Sum & Average & Variance \\
\hline Group A & 28 & 684 & 24.4285 & 47.6613 \\
\hline Group B & 28 & 571 & 20.3928 & 53.6547 \\
\hline Group C & 28 & 561 & 20.0357 & 44.1838 \\
\hline
\end{tabular}

Anova table - second part

\begin{tabular}{|l|c|c|c|c|c|c|}
\hline $\begin{array}{l}\text { Source of } \\
\text { Variation }\end{array}$ & $S S$ & $d f$ & $M S$ & $F$ & $P$-value & $F$-crit \\
\hline Between Groups & 333.3095 & 2 & 166.65 & 3.4361 & 0.0369 & 3.1093 \\
\hline Within Groups & 3928.5 & 81 & 48.5 & & & \\
\hline Total & 4261.81 & 83 & & & & \\
\hline
\end{tabular}

We were also interested in the fact which two of three used methods are significantly different in their effectiveness. The MS Excel program does not operate with statistical programs for these kinds of file comparisons, therefore we used Duncan's test for the statistical significance of contrasts.

The average numbers of points were arranged according to their size:

$$
\bar{x}_{1}=24.42 ; \bar{x}_{2}=20.39 ; \bar{x}_{3}=20.03
$$

The value of tested criterion was calculated, given $S_{r}^{2}$ as a residual dispersion

$$
\sqrt{\frac{s_{r}^{2}}{n}}=\sqrt{\frac{48.5}{28}}=1.31
$$

The relevant tables were used for the determination of critical values of Duncan's test $D_{0.05}$ for the significance level $\alpha=0.05$ for given $p$ and given residual number of degrees of freedom $84-3=$ $=81$. These data were entered into the Table 5 together with the calculated values $D_{p, a}$.

The critical values of Duncans test

Tab. 6

\begin{tabular}{|c|c|c|}
\hline$p$ & $D_{0,05}$ & $D_{p, a}=D_{0,05}$ \\
\hline 2 & 2.814 & 3.686 \\
\hline 3 & 2.961 & 3.878 \\
\hline
\end{tabular}

By the means of these characteristics we tested statistical significance of the particular arithmetic averages

We tested the following differences:

For the difference $\bar{x}_{1}-\bar{x}_{3}$ we got:

$p=3, D_{p, \alpha}=3.878$. As $\bar{x}_{1}-\bar{x}_{3}=4.39>3.878$ difference is significant.

For the difference $\bar{x}_{1}-\bar{x}_{2}$ we got:

$p=2, D_{p, \alpha}=3.686$. As $\bar{x}_{1}-\bar{x}_{2}=4.03>3.878$ difference is significant.

For the difference $\bar{x}_{2}-\bar{x}_{3}$ we got:

$p=2, D_{p, \alpha}=3.686$. As $\bar{x}_{2}-\bar{x}_{3}=0.37<3.878$ difference is not significant.

The testing showed that the teaching method $A$ is more effective than the methods $B$ and $C$.

\section{Interpretation of the results}

The innovative teaching used in education was proved by the statistical testing as a convenient means to increase students' performance in mathematics. We afford to say that the results are sufficient enough to accept the claim that the students taught by the innovative method $A$ and actively using the information technologies, acquired more competencies from the curriculum than the students taught by the methods $B$ or $C$.

The experimental method proved itself as valid and reliable. The results of experiment clearly indicate that the integration of information technologies into the educational process is not sufficient if it is not accompanied by the participation of students and their active engagement in the process of education. Otherwise we may talk only about showy teaching, but not about effective teaching.

The sample size used for testing does not authorize us to generalize our statement. However, we may conclude that the results obtained in the experiment are in consonance with the results of similar researches, such as Tall's research [4].

\section{Acknowledgement}

This work was supported by grant of the Slovak Grant Agency KEGA, Project No. 046ZU - 4/2011: The Information Age Modifies the Forms and Methods of Teaching Mathematics.

\section{References}

[1] KILPATRICK, J., DAVIS, R.: Computers and Curriculum Change. In: Mathematics Education and Technology: Computers and System Science, vol. 121, 1993, pp. 135-142. 


\section{COMMNICOIIONS}

[2] KONTROVA, L.: Method "Learning by Doing" with MS Excel. In: XXIV. Intern. Colloquium on the Acquisition Process Management, Brno Univerzity of Defence, Faculty of Economics and Management, 2006, ISBN 80-7231-139-5. pp. 235-246. [3]

[3] KRYGOWSKA, Z.: Zarys dydaktyki matematyki. [Introduction to Mathematics Education], WSP, Warszawa, 1977. pp. 111-127.

[4] POBOCIKOVA, I.: Better Confidence Intervals for a Binomial Proportion. Communications - Scientific Letters of the University of Zilina, Vol. 12, ZU: Zilina, 2010, ISSN 1335-4205. pp. 45-49.

[5] TALL, O.: Cognitive Development in Advanced Mathematics Using Technology. In: Mathematics Education Research Journal, 2000, vol. 12, No 3 .

[6] TRIOLA, M.: Elementary Statistics. New York, 1989, ISBN 0-8053-0271-9. pp. 357-389. 